Research Article

\title{
Research on E-Commerce Purchasing Model in Crude Oil Trade
}

\begin{abstract}
Yunfei Li (iD
Xijing University, Xi'an 710123, China

Correspondence should be addressed to Yunfei Li; 20130044@xijing.edu.cn

Received 24 March 2021; Revised 9 April 2021; Accepted 20 April 2021; Published 24 April 2021

Academic Editor: Shah Nazir

Copyright (c) 2021 Yunfei Li. This is an open access article distributed under the Creative Commons Attribution License, which permits unrestricted use, distribution, and reproduction in any medium, provided the original work is properly cited.

Crude oil is the main raw material for the petrochemical industry and a major component of total production costs. It is also an indispensable resource for petrochemical enterprises. The implementation of crude oil e-commerce procurement by petrochemical enterprises can not only reduce the procurement cost of crude oil but also create good economic benefits in the field. It can also establish strategic partnerships with oil field enterprises to lay the foundation for the scientific development of enterprises. Based on the production of Company A and the "10 Million Tons Refining" project, this paper introduces the concept of e-commerce procurement for the problems in all aspects of crude oil procurement management. This paper deeply studies the e-commerce procurement theory, constructs the e-commerce procurement management implementation framework, and proposes that the scientific evaluation of crude oil suppliers is the key idea for petrochemical enterprises to implement enterprise e-commerce procurement management. At the same time, it also conducted an in-depth analysis of the internal and external environment of a company's crude oil e-commerce procurement, conducted a comprehensive evaluation of existing crude oil suppliers and potential suppliers, and formulated corresponding procurement strategies. Results of the study show the success of the proposed study, and on the basis of the proposed study, researchers can devise new solutions in the field.
\end{abstract}

\section{Introduction}

The development of computer networks and communication technologies has made the processing and transmission of information technology break through the limitations of time and region. The network and globalization of the economy have become an inevitable trend in the development of the world economy. The new economic model has challenged the traditional business model, and the emergence of e-commerce has adapted to the rapid development of the requirements of the new economic development [1]. E-commerce not only provides enterprises with new development space but also provides enterprises with new ways to enhance their competitive advantage. E-commerce will become the main form of trade in the era of the knowledge economy. If enterprises do not seize the opportunity to develop e-commerce, they will be eliminated by the market, and it is imperative for enterprises to develop an e-commerce [2].

International research on e-commerce began in the late 2000 s and was only booming at the end of the century. As for the concept of e-commerce, people have different opinions depending on the angle and field of the station, and there is no exact definition [3]. Generally speaking, e-commerce is an electronic transaction, that is, conducting business activities online, and is a commercial trade activity conducted by people through the Internet. When an enterprise directly connects its main business through intranets, extranets, and employees, customers, vendors, and partners, the various activities that take place are e-commerce.

E-commerce in China began in 1997 and developed rapidly. According to the monitoring data of China Electronic Commerce Research Center, the transaction scale of China's electronic commerce market reached 1.02 trillion yuan in 2013, accounting for $17.3 \%$ of GDP. China's e-commerce has been developing at a rapid speed. More and more industries and enterprises realize that only by speeding up the development of e-commerce can they keep up with the pace of industry development. E-commerce has become an indispensable business channel for modern enterprises, even the commanding heights of enterprise competition. In the world petroleum and petrochemical 
market competition, more and more new technologies such as e-commerce platforms have been used to reduce transaction costs and improve customer service. The main competitors of foreign petroleum and petrochemical enterprises actively penetrate the domestic market and directly participate in the domestic competition, which will bring pressure to the petroleum and petrochemical enterprises of China. If the petroleum and petrochemical enterprises of China do not adopt the advanced e-commerce management mode in time, it will be difficult for them to participate in the world competition. However, the e-commerce system currently used by petroleum and petrochemical enterprises is still not perfect: poor security of online payment, imperfect logistics system, relative lack of required compound talents, weak marketing system, etc., will restrict the application of e-commerce in petroleum and petrochemical industry to play its greatest strength. Therefore, it is necessary to constantly improve the electronic commerce system in order to ensure the steady development of the petroleum and petrochemical industry.

According to the definition of business model, you can participate in the main business and individual consumers as two dimensions according to business activities and divide the e-commerce business model into the following four categories: B2B, B2C, C2B, and C2C. In a traditional supply chain, a product manufacturer often connects several levels of supplier nodes. These suppliers mainly include raw material suppliers, outsourced manufacturers, and in-house manufacturers, which are more complex supply chain networks downstream of the supply chain, as shown on the left in Figure 1.

Based on this, this article takes Company A as the research object and conducts a series of researches around e-commerce. Company A is located in Jilin City, Jilin Province. It is the country's first large-scale chemical industrial base built during the "First Five-Year Plan" period. This paper first analyzes the supply and demand situation of crude oil procurement resources of Company A. Then, it deeply analyzes the various drawbacks of the original traditional procurement model of Company A, compares the economic benefits brought by the use of e-commerce procurement, and discusses the inevitability of Company A's e-commerce model for crude oil procurement. Finally, combined with the characteristics of crude oil procurement of petrochemical enterprises, this paper constructs an evaluation index system for crude oil strategic procurement plan of petrochemical enterprises according to the principle established by the evaluation index system.

The contribution of the paper is to deeply study the e-commerce procurement theory, construct the e-commerce procurement management implementation framework, and propose that the scientific evaluation of crude oil suppliers is a vital idea for petrochemical enterprises to implement enterprise e-commerce procurement management. It also conducted an in-depth analysis of the internal and external environment of a company's crude oil e-commerce procurement, conducted a comprehensive assessment of prevailing crude oil suppliers and possible suppliers, and formulated corresponding procurement strategies.

\section{Related Work}

In the past, in many organizations, procurement was considered to be an unimportant function, and its role and influence in the enterprise were relatively low as a supporting role. Until the 21st century, people have a preliminary understanding of the strategic importance of procurement and its importance for reducing organizational costs. E-commerce procurement is regarded as the source of the enterprise value chain and plays a vital role in the construction of enterprise competitiveness. The focus of enterprise management becomes the further integration of procurement management and the entire business process of the enterprise. The development of world-class concepts, lean supply, value chains, etc. requires a strategic and dynamic procurement function. $\mathrm{Lu}$ outlines the definition of e-commerce procurement: e-commerce procurement is the process of planning, implementing, and controlling strategic and operational procurement decisions [4]. The purpose is to guide all activities of the procurement department around improving the company's capabilities to achieve the company vision plan. E-commerce procurement emphasizes the process of establishing a service supply channel at the lowest total cost. One of its core issues is "total cost". Several other issues are supplier selection, information sharing, and quality issues. Wang pointed out that the company's e-commerce management level determines the level of e-commerce procurement of enterprises to a certain extent [5].

With regard to research on supplier partnerships and strategic alliances, research in the literature shows that supplier alliances bring better market expansion, new technologies and knowledge, and higher return on investment, but the rate of failure is also high; probably, it is $60 \%$ to $70 \%$. This shows that a successful strategic alliance requires the two sides to fulfill their commitments learn from each other and strengthen information communication on the issue of coordinated development, rather than simply providing assistance or convening a seminar to solve a problem. An H refers to partnerships in the supply and demand chain as supply alliances, stating that partnerships must be beneficial to both parties [6]. Al-Somali et al. pointed out that partnerships are a long-term commitment and agreement between buyers and suppliers, including information sharing and sharing and sharing of benefits and risks due to partnerships [1]. In other words, the concept of a partner must be based on cooperation and trust. They looked at an example of how to use reverse marketing methods to find qualified suppliers and considered this to be the basis for successful partnerships. Guan pointed out that in order to improve the efficiency of the supply chain, it is more important to build partnerships than information technology, because partnerships are a prerequisite for the successful use of IT [7]. Valmohammadi analyzed the factors that hindered the internationalization of procurement, such as distance, time zone differences, consumer behavior differences, and monetary and financial differences [8]. At present, e-procurement has become an indispensable means of establishing a competitive advantage for enterprises. The development of e-procurement has a huge impact on the global economy. 

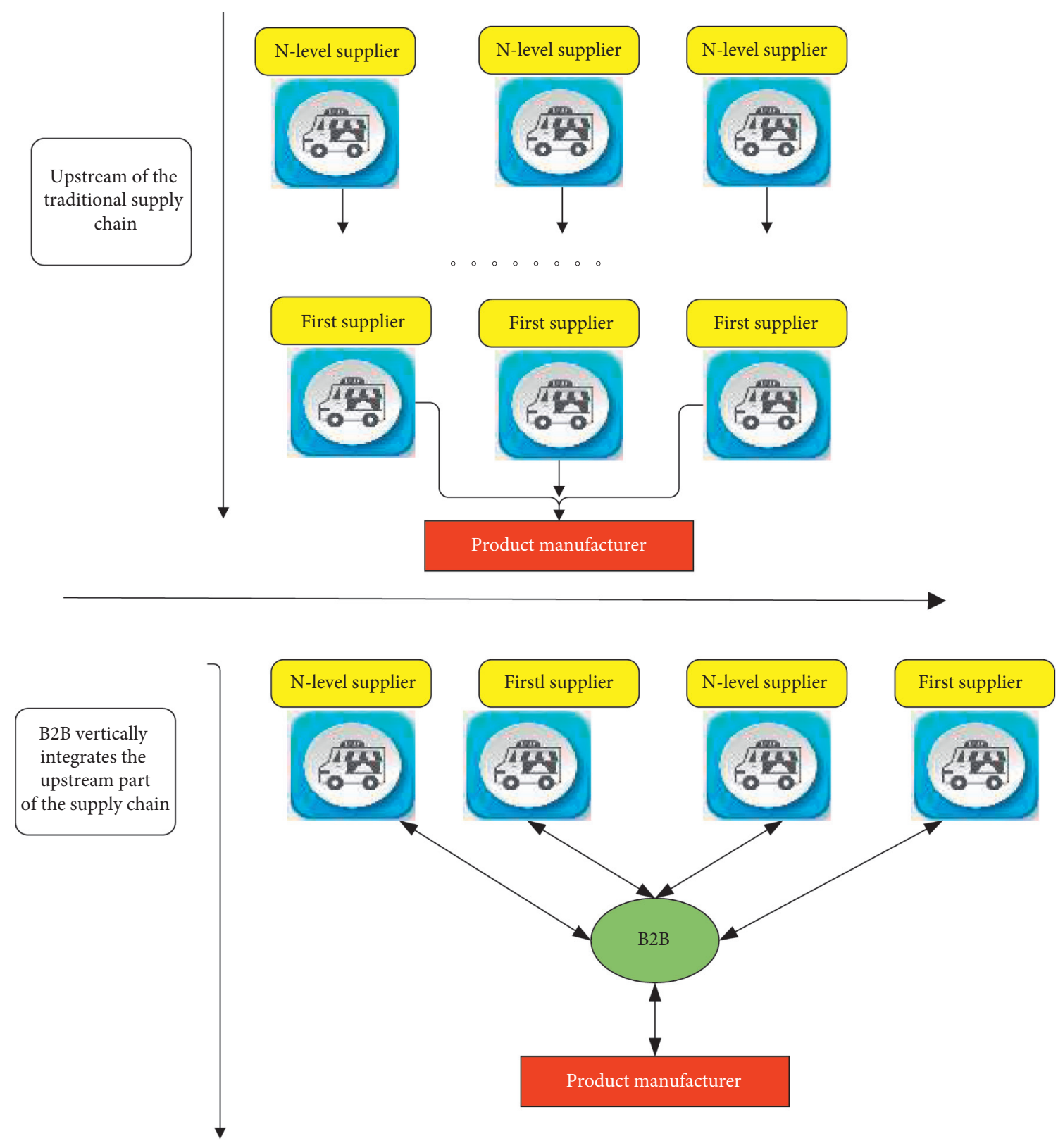

Figure 1: B2B impact on the upstream part of the supply chain.

\section{Analysis of Supply and Demand Situation of Crude Oil Procurement Resources of Company A}

In a traditional supply chain, a product manufacturer often connects several levels of supplier nodes. These suppliers mainly include raw material suppliers, outsourced manufacturers, and in-house manufacturers, which are more complex supply chain networks downstream of the supply chain, as shown on the left in Figure 1 [9]. However, in the e-commerce environment, through the procurement platform, product manufacturers can achieve not only the vertical integration of several upstream suppliers but also the best way to select the best products and the best in the world. The partner is shown on the right in Figure 1. The B2B model transforms the "bargaining" relationship between product manufacturers and suppliers into a win-win "partnership" relationship, eliminating unnecessary waste and operations on the supply chain network, and promoting the supply chain to be dynamic, virtual, and global. The direction of networking is developing. Compared to the $\mathrm{B} 2 \mathrm{C}$ model, $\mathrm{B} 2 \mathrm{~B}$ achieves a deeper change in the enterprise supply chain.

3.1. International Crude Oil Resource Supply Situation. The global demand for oil is increasing, and the price of crude oil continues to reach a high level, and the core position of oil as an important energy source cannot be shaken in a short period of time. Although the current crude oil price has fallen to a low point, with the economic 
recovery and extreme concerns about inflation, a rise in crude oil prices is expected. The international oil price is obviously affected by the trend of the US dollar and the US economy. The reduction of oil companies has added more variables to the world economy, and it is also directly linked to the fluctuation of the US dollar exchange rate. Oil production cuts are undoubtedly factors that cannot be underestimated in the economic recovery. The International Energy Agency, the source and state regulator, predicts that by current prices, by 2020 , OPEC will need to increase its daily output from 30 million barrels to 50 million barrels to meet rising demand. But Saudi senior energy officials warned the US and European counterparts that it is extremely difficult for OPEC to meet this level of demand. According to Saudi calculations, there will be a gap of 4.5 million barrels between the global demand for oil produced by Saudi Arabia and the capacity that Saudi officials believe can be achieved. As shown in Table 1, the world's top ten crude oil producers rank first in the world in terms of Saudi oil reserves and will shoulder half of OPEC's production growth in the next 10 to 20 years. The rest will be mainly from Kuwait and the United Arab Emirates. Although global oil demand continues to rise, OPEC's oil production is nearing its limit, and the space for oil production is gradually reaching its peak, while global oil giants are facing the test of oil production cuts. Although the world has made certain breakthroughs in new energy development, the key to the problem is that the cost of use is too high, making it difficult to gain popularity in the short term. At present, the competition for petroleum resources in the world is becoming increasingly fierce. The strategic layout of the United States in global energy competition has taken shape, and the fast-growing economies such as China, Japan, and India are all in the energy industry [10]. We expect the EU to make strategic adjustments in energy in the coming period. Various economies around the world are strategically deploying around energy issues, and this energy competition is expected to intensify as global oil production capacity approaches its limits. The world's top ten original producing countries are shown in Table 1.

\subsection{Domestic Crude Oil Resource Supply Situation.} China's oil is mainly consumed in the industrial sector, followed by transportation, agriculture, commerce, and consumer spending. Among them, the proportion of industrial oil consumption in the total oil consumption of the country has been maintained at more than 50\%. Transportation oil consumption is second only to industry, accounting for about $25 \%$. The proportion of oil consumption in agriculture, forestry, animal husbandry, fishery, and water conservancy accounts for less than $10 \%$ of total oil consumption. The proportion of domestic consumption of oil to total oil consumption is only about $6 \%$. According to data released by the customs, the top five countries in China's crude oil imports in 2017 are Saudi Arabia, Angola, Iran, Russia, and Oman. The total import growth of the five countries to China's crude oil suppliers is between $3.7 \%$ and $22.4 \%$ [11].
Oil is an important strategic material that plays a pivotal role in the national economy. At present, in China's onetime energy consumption, oil consumption accounts for 17$18 \%$. With the rapid development of China's national economy and the continuous improvement of the level of industrialization, the demand for high-quality energy such as petroleum is increasing, and the petroleum industry has gradually become a bottleneck restricting the development of the national economy. Therefore, measures must be taken to promote the healthy and stable development of China's oil industry and ensure the balance of supply and demand of China's oil. In summary, the rise in crude oil prices is an inevitable trend unless humans find alternative energy sources. International crude oil prices have an important impact on the world economy, production efficiency, balance of payments, social price levels, and international relations [4]. Countries are paying close attention to their trends in order to facilitate the healthy development of their economies and establish a good diplomatic environment. As a large-scale enterprise in China's petrochemical industry, Company A's demand for crude oil is increasing, and the strategic management of crude oil procurement will be extremely important.

\section{Comparative Analysis of the Advantages of E-Commerce Procurement Model}

4.1. Traditional Procurement Model. Company A is a large state-owned enterprise established more than 50 years ago. For a long time, the company mainly exists as a raw material producer of the petrochemical group, and the material management method has been following the model of the planned economy period. There are many problems such as long cycles, low efficiency, slow response, high inventory, and high capital occupation. Its traditional procurement process is shown in Figure 2.

However, Company A's traditional procurement model has the following drawbacks:

(1) There are too many organizational levels, and people are overstaffed. It can be seen from the traditional material procurement flow chart that in order to complete the material procurement task, the corresponding organizational structure and personnel must be set up to complete the corresponding procurement business. In particular, in the search for suppliers and consulting prices, there must be a large number of personnel and complicated procedures to complete. Buyers are running around the world to find and evaluate suppliers. Sometimes, in order to find a reasonable price, the buyer has to run many places. By looking for suppliers in a variety of ways, such as telephone and fax, it is possible to find materials that you can accept and then to determine the price and variety [12]

(2) The channel is single and the supply is unstable. The channel mentioned here is not only a channel for material procurement but also a channel for information acquisition. In the traditional material 
TABLE 1: The world's top ten original producing countries.

\begin{tabular}{lcc}
\hline Ranking & Country & Daily average crude oil production (10,000 barrels) \\
\hline 1 & Saudi Arabia & 1085.9 \\
2 & Russia & 976.9 \\
3 & United States & 687.1 \\
4 & Iran & 434.3 \\
5 & China & 368.4 \\
6 & Mexico & 368.1 \\
7 & Canada & 296.6 \\
8 & United Arab Emirates & 282.2 \\
9 & Venezuela & 279.8 \\
10 & Norway & 277.3 \\
\hline
\end{tabular}

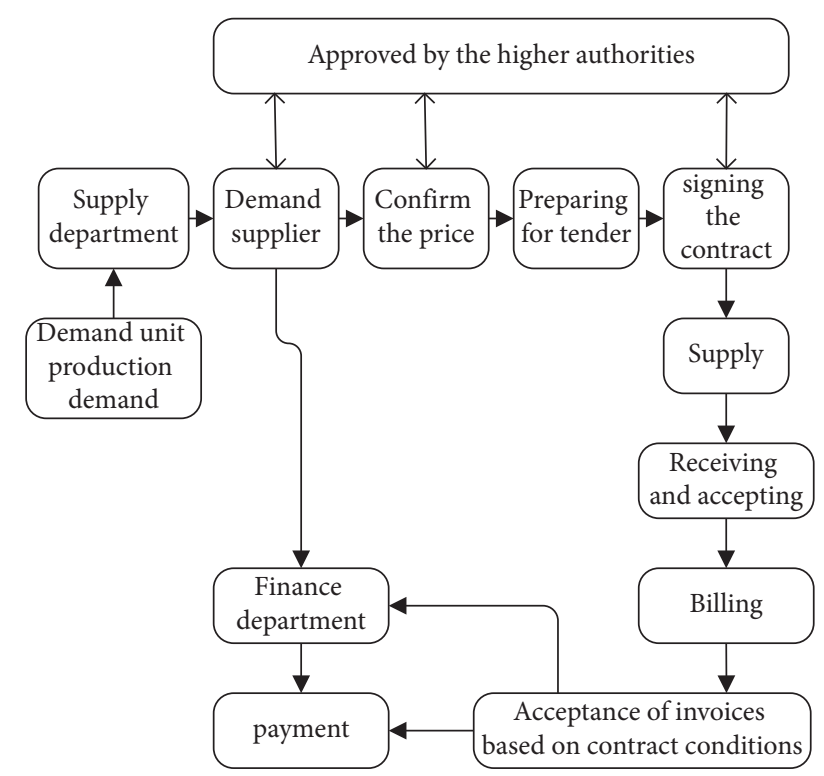

FIGURE 2: A company's traditional procurement model diagram.

procurement process, the first thing the factory has to do is to prepare before the transaction. For the trading process, pretransaction preparation is the process of how the supply and demand sides can promote or obtain effective product information. The marketing strategy of the supplier of the goods is to promote their own product information through various forms of advertising such as newspapers, television, and outdoor media. For the needs of the goods-enterprises and consumers, you should get the information you need as much as possible to enrich your purchase channels. Therefore, the preparation before the transaction is actually a process of publishing, inquiring, and matching the product information. For buyers, they mainly obtain information about the items they need and the companies that produce them through newspapers, magazines, television, outdoor media, online catalog flyers, and so on. However, the information obtained in this way is always unreliable, and a large number of manpower and material resources have to be dispatched to find out the authenticity of the product and the enterprise. Even so, it is often difficult to get the real information you need. In addition, the choice of suppliers is also very random, and there is no longterm partnership, which may lead to the purchaser's purchase, supply, and production disjoint

(3) The procurement cost is too high. As mentioned above, obtaining information requires a certain amount of cost, and the information of both parties is not shared because the transaction between the buyer and the seller is based on a zero-sum strategy and is a hostile relationship. The profit of such a party is based on the loss of the other party, so the information of both parties is kept secret to the other party

(4) High inventory costs: In the traditional production process, in order to ensure the production of the required materials, the material procurement department always builds a large number of warehouses to gather a large number of regular materials in production; otherwise, it will not be able to meet production. This will take up a lot of money and directly affect the normal flow of corporate funds

(5) Long procurement cycle: The actual operation in the traditional material procurement process consists of pretransaction preparation, contract negotiation, contract execution, and contract settlement. The material procurement department starts from the information of the material demand plan, to find information, business negotiation, material transportation, and other aspects. In the end, the materials that arrive at the demand department (such as various production workshops) take a long time, which is one or two weeks, and several months. After such a long period of time, some materials were needed at that time. After waiting for a long time, due to changes in production processes and technologies, the purchased materials could no longer meet the production needs. These problems are often encountered [13]

Through the above analysis of the shortcomings of the traditional procurement model, it can be seen that the model is no longer suitable for the survival and development of enterprises under the market economy. So what can be done to solve or improve? With the rapid development of the Internet, e-commerce work and e-commerce procurement 
have become indispensable technical means to promote continuous restructuring, strengthen management, reduce production and operation costs, and enhance market competitiveness.

4.2. Crude Oil Procurement Model under E-Commerce. E-commerce procurement is a procurement model in the e-commerce environment, also known as online procurement. E-commerce procurement is a new way of purchasing along with the development of the information society. E-commerce purchases are companies that publish supply and demand information or find suitable suppliers and items via the Internet. E-commerce procurement activities are realized through online product understanding, online negotiation, online comparison, online bidding, online ordering, and online payment. E-commerce procurement is a new procurement model that enables all-day, worldwide, and transparent procurement activities. It is beneficial to shorten the procurement time, reduce the cost of purchasing, reduce the purchase inventory, and achieve the efficiency of enterprise procurement [14].

E-commerce procurement can search for information of products from the Internet through the Internet, which is beneficial for enterprises to collect all product information when purchasing and to do the comparison when there is no need to travel and go to the market to see the goods. This is a great aspect of the progress of corporate procurement and the efficiency of corporate procurement. The process of e-commerce mining from the process of product understanding, product negotiation, product price comparison, product bidding, product ordering, payment, etc. is carried out online without the need to negotiate. This is conducive to the transparency of the procurement process and can effectively reduce the problem of corruption in the procurement process. At the same time, after e-commerce procurement conducts product transactions online, logistics can quickly deliver products to the enterprise, which helps to shorten the procurement cycle.

\subsubsection{Characteristics of E-Commerce Procurement.} E-commerce procurement is a new procurement model, which can achieve an all-day, full-efficiency world and full transparency of purchasing activities. It is beneficial to shorten the procurement time, reduce the cost of purchasing, reduce the purchase inventory, and achieve the efficiency of enterprise procurement.

E-commerce procurement from the product understanding, product negotiation, product price comparison, product open bidding, product ordering, payment, and other processes is carried out online without the need to face the transaction, which is conducive to the open and transparent procurement process. There is no distance or border on the Internet, and any supplier can bid to the purchasing industry for a wide range of industries. The purchaser has also made a targeted selection based on the supplier's situation. In the process of e-commerce procurement, publishing supply and demand information or finding suitable suppliers and interactive items is done through the Internet. The information between the purchaser's enterprise and the supplier is also exchanged through the network, which is a convenient, fast, and lowcost network. E-commerce procurement can search for information on products from the Internet through the Internet, which is beneficial for enterprises to collect all product information when purchasing. In the case of no need to travel and go to the market, low-cost manufacturers to see the goods compared to the situation, to achieve a shop-by-shop, can be said to save money, save time, save people, and save the workload [15].

E-commerce procurement activities can be realized through online product understanding, online negotiation, online comparison, online bidding, online high-speed ordering, online payment, etc. After e-commerce purchases are conducted online, the products can be quickly sent to the products. The summary is shown in Figure 3.

\subsubsection{Procurement Model in E-Commerce Environment.} Material procurement and management play an important role in the enterprise and are the key to the integration of internal and external resources. At present, in the traditional material procurement process of Company A, the structure is bloated, huge, and people are overstaffed. The problems in the management of mining and management have seriously affected the development of the entire company and the improvement of market competitiveness. In the material procurement process in the modern e-commerce environment, how can the process be set up to complete the procurement task and adapt to the needs of the times? As an effective way to change the status quo of a company's procurement management, in the process of process reengineering, the flat procurement rules should be followed, and the material procurement process should be reengineered in the e-commerce environment [16]. The procurement flow chart is shown in Figure 4.

We set up a special supplier management department in the material supply department to increase the dynamic evaluation of suppliers' supply capacity, material quality, and supply speed, eliminate unqualified suppliers, and motivate excellent suppliers. We optimize the supply chain of Company A through the management of suppliers. Company A has reorganized the material procurement organization and strengthened the original material supply department. It is directly affiliated with Company A and has unified planning, unified procurement, and unified management of the materials required by the entire company. The original decentralized procurement mechanism was transformed into centralized procurement and management, which strengthened the company's control and management of material procurement. In addition, the Materials Supply Department has set up a special supplier management department, which is responsible for the management of suppliers, strengthens the ability of Company A to integrate external resources, and is conducive to the establishment of an effective supply chain. After the reorganization, the entire company's procurement philosophy and procurement operations have undergone great changes [17], as shown in Table 2. 


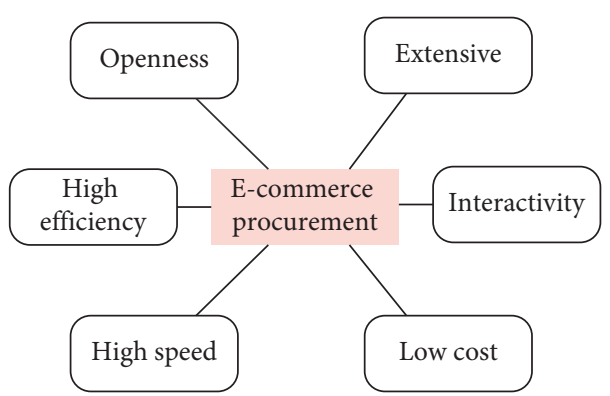

Figure 3: Characteristics of e-commerce procurement.

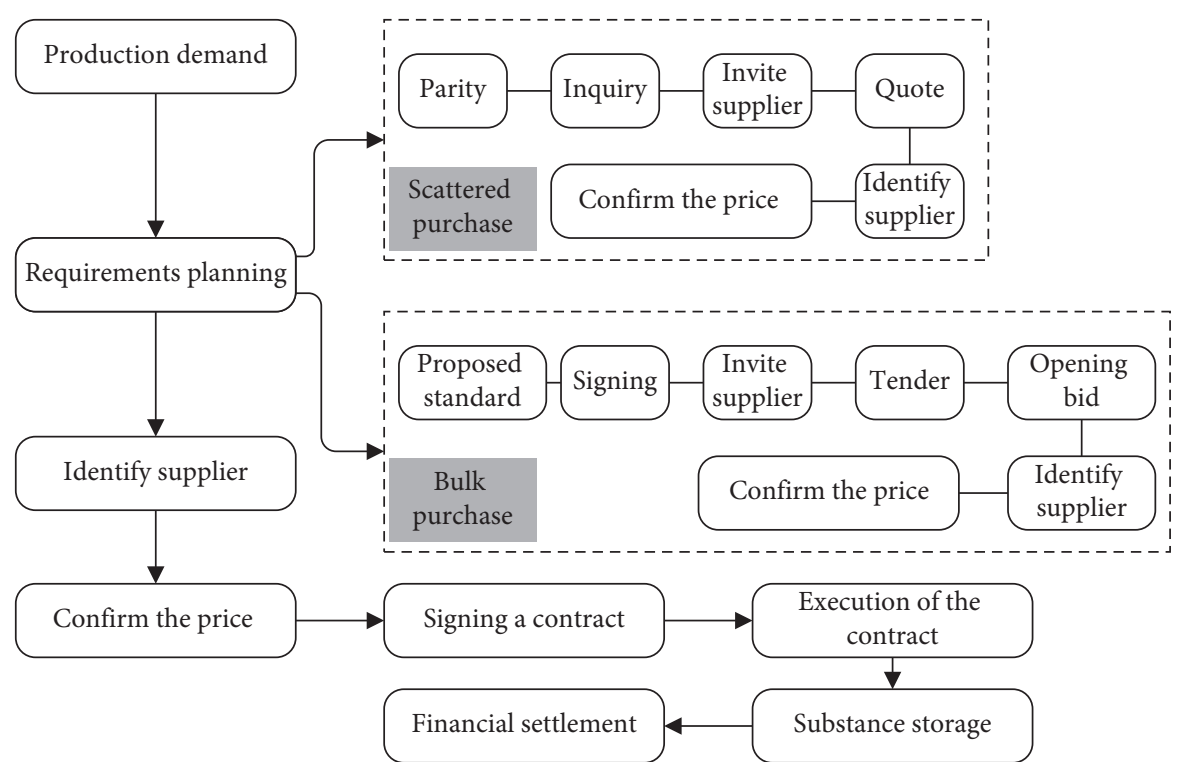

FIgURE 4: A company's overall e-commerce procurement process.

TABLE 2: Comparison of the company's traditional procurement model and e-commerce-based procurement model.

\begin{tabular}{lc}
\hline Project & Traditional procurement model \\
Drive mode & $\begin{array}{c}\text { Inventory plan } \\
\text { Departmental focus }\end{array}$ \\
$\begin{array}{c}\text { Commodity trading activities with suppliers, such as } \\
\text { price negotiations, signing contracts, arranging } \\
\text { transportation, and goods acceptance }\end{array}$ \\
Departmental nature & $\begin{array}{c}\text { An auxiliary department within the enterprise that } \\
\text { manages the procurement activities of the enterprise }\end{array}$ \\
Work goals & Complete the purchase plan and reduce the purchase \\
price
\end{tabular}

Purchasing behavior Purchase cost Control of quality, quality, and delivery time

Exchange of information with suppliers

Number of suppliers
Mostly one or a few

Doron negotiations, consultation, high cost

Ex post control

Asymmetry

Multiple, encourage, and compete
E-commerce procurement model

Production demand plan

Inspection and evaluation of suppliers, operation of procurement plans, supplier information maintenance and substance acceptance, feedback

The outward-oriented pioneering department of the enterprise develops and manages the external resources of the enterprise

Ensure the material needs of the production sector, actively develop external resources, find or cultivate excellent suppliers, and guarantee competitive advantage Teamwork

Program simplification and cost reduction

Strict selection and evaluation of suppliers, feedback on the use of prior control

Information sharing

A small number of partnerships that encourage cooperation 
TABLE 3: General indicators of crude oil supplier evaluation.

\begin{tabular}{lcc}
\hline Overall target layer & Primary indicator & Secondary indicators \\
\hline & & Light oil yield \\
Density \\
Moisture \\
Sulfur content \\
General indicator of crude oil supplier evaluation & Crude oil quality & Crude oil prices \\
& & Transport fees \\
& Purchase cost & Financial expenses \\
& & Future sustainable mining capabilities \\
& Policy impact & Cost of mining \\
\hline
\end{tabular}

From this point of view, under the centralized procurement model, the organizational structure of enterprises has undergone tremendous changes compared to the decentralized procurement model. Each subsidiary and secondary accounting unit does not have its own independent procurement department. They focus on their procurement department (Material Supply Division) by presenting their own procurement needs to the company's only centralized purchasing department. Through the collection and unification of various needs, a large purchase order is formed, and the demand is satisfied through various procurement methods such as bidding procurement, price comparison procurement, advanced source procurement, and special procurement of shortage products [18], thereby reducing procurement costs and improving procurement quality and efficiency.

\section{Construction of Supplier Evaluation Index System in Procurement Mode}

5.1. Establishment of the Indicator System. The relevant research results of this study used the evaluation indicators to evaluate the crude oil suppliers of Company A, which are crude oil quality, procurement cost, and potential. The overall indicators are shown in Table 3.

5.2. Construction of Supplier Indicator System. Crude oil is the main raw material of refinery equipment. The quality of crude oil, the cost of procurement, and the potential of suppliers are the key to the safe and stable production and operation efficiency of enterprises. It is also the key to the smooth production and optimization of chemical equipment. The above indicators must be considered in the selection of suppliers. Establishing a scientific indicator system for suppliers is conducive to optimizing the structure of crude oil procurement, reducing procurement costs, and ensuring smooth operation of the equipment. The data of the supplier indicator system is processed by the analytic hierarchy process, as shown in Figure 5 [21].

We establish a supplier database based on the supplier's relevant information and analyze and process the data. The supplier data of Supplier A's supplier index system is evaluated by the expert research method, and the data is classified and scored. Based on this, a comprehensive

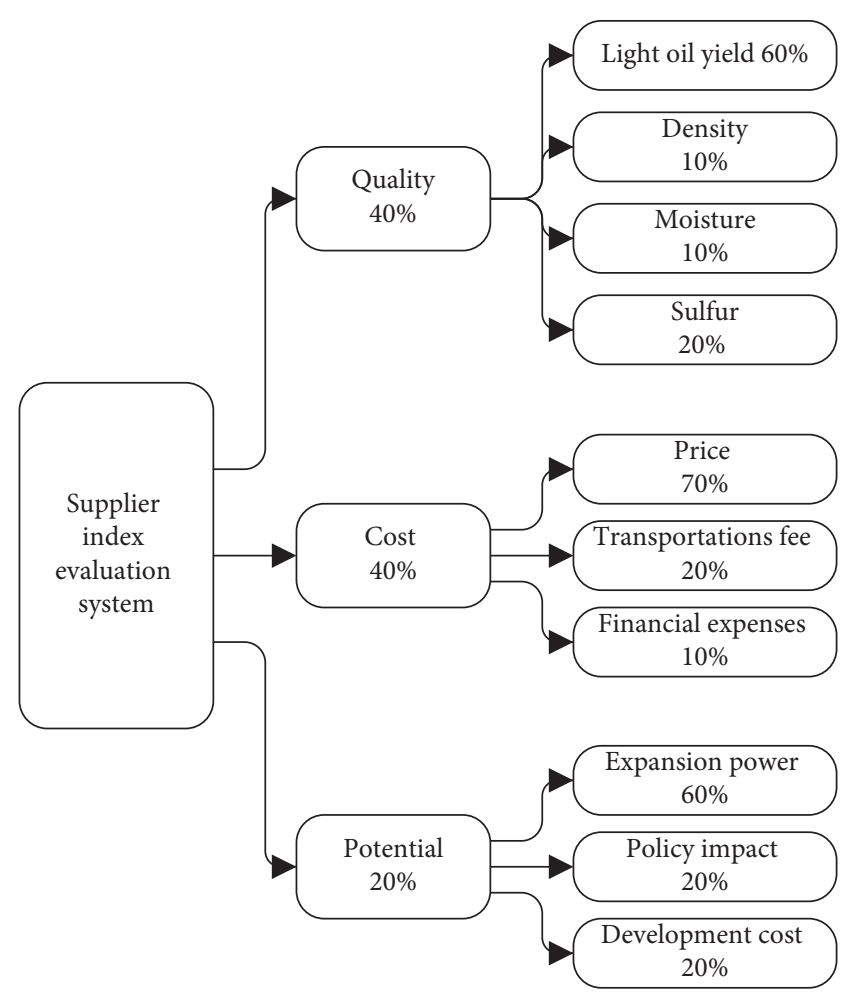

FIgURE 5: Hierarchical analysis of supplier indicators.

evaluation is carried out. The supplier's scoring data is shown in Tables 4-6.

5.3. Determination of Calculation Results and Allocation of Procurement Ratio. According to the above data, the supplier is evaluated. The results are shown in Table 7.

After calculation, each supplier can be divided into four files: A, B, C, and D. A is a Russian import crude oil supplier; the Russian crude oil supplier comprehensive evaluation score is the preferred supplier, although its procurement cost is high, its crude oil quality is high, and its future sustainable development ability is strong; B is Inner Mongolia Cooperative Oilfield and Jilin Oilfield; C is Huadian shale oil; D is a Shuangyang foreign-funded cooperative oilfield and Daqing Oilfield.

Company A's crude oil processing capacity will reach 10 million tons/year. According to the above data analysis 
TABLE 4: Supplier's crude oil quality data.

\begin{tabular}{lccccc}
\hline Supplier & $\begin{array}{c}\text { Daqing } \\
\text { oilfield }\end{array}$ & $\begin{array}{c}\text { Jilin } \\
\text { oilfield }\end{array}$ & $\begin{array}{c}\text { Russian } \\
\text { imports }\end{array}$ & $\begin{array}{c}\text { Inner Mongolia } \\
\text { cooperation }\end{array}$ & $\begin{array}{c}\text { Shuangyang foreign investment } \\
\text { cooperation }\end{array}$ \\
\hline Light oil yield & 27.3 & 26.5 & 58.3 & 39.5 & 21.2 \\
Score & 7 & 7 & 10 & 9 & 6 \\
Density (20 Cg/ & 0.8356 & 0.8631 & 0.8221 & 0.8281 & 0.8812 \\
cm) & 9 & 9 & 10 & 10 & 8 \\
Score & 0.06 & 0.06 & 0.09 & 0.13 & 0.10 \\
Moisture $\%$ & 10 & 10 & 8 & 6 & 7 \\
Score & 0.16 & 0.16 & 0.68 & 0.10 & 0.18 \\
Sulfur content $\%$ & 9 & 9 & 5 & 10 & 7 \\
Score & & & & & \\
\hline
\end{tabular}

TABLE 5: Formula to purchase the cost of crude oil from various suppliers.

\begin{tabular}{lccccc}
\hline Supplier & $\begin{array}{c}\text { Daqing } \\
\text { oilfield }\end{array}$ & $\begin{array}{c}\text { Jilin } \\
\text { oilfield }\end{array}$ & $\begin{array}{c}\text { Russian } \\
\text { imports }\end{array}$ & $\begin{array}{c}\text { Inner Mongolia } \\
\text { cooperation }\end{array}$ & $\begin{array}{c}\text { Shuangyang foreign investment } \\
\text { cooperation }\end{array}$ \\
\hline Price & 5886 & 5886 & 6219 & 5055 & 5055 \\
Score & 7 & 7 & 6 & 8 & 8 \\
Transport fees & 70 & 51 & 70 & 89 & 32 \\
Score & 7 & 8 & 7 & 6 & 10 \\
Financial & 45 & 45 & 75 & 85 & 35 \\
expenses & 8 & 8 & 5 & 8 & 10 \\
Score & & & & &
\end{tabular}

TABle 6: Supplier's sustainability capabilities.

\begin{tabular}{lccc}
\hline Supplier & Capacity expansion potential & Policy support & Development costs \\
\hline Daqing oilfield & 6 & 10 & 10 \\
Jilin oilfield & 8 & 10 & 7 \\
Russian imports & 9 & 9 & 9 \\
Inner Mongolia cooperation & 4 & 8 & 7 \\
Shuangyang foreign investment cooperation & 4 & 4 & 5 \\
\hline
\end{tabular}

TABLE 7: Calculation results of supplier evaluation indicators.

\begin{tabular}{lr}
\hline Supplier & Comprehensive evaluation score \\
\hline 1. Daqing oilfield & 6.87 \\
2. Jilin oilfield & 7.95 \\
3. Russian imports & 8.59 \\
4. Inner Mongolia cooperation & 8.38 \\
5. Shuangyang foreign investment cooperation & 6.94 \\
Average value & 7.746 \\
\hline
\end{tabular}

TABLE 8: A company's crude oil procurement allocation table.

\begin{tabular}{lccc}
\hline Supplier & Existing capacity constraints & Sulfur content of crude oil & Allocation amount \\
\hline Daqing oilfield & 5500 & 0.18 & 25 \\
Jilin oilfield & 560 & 0.17 & 500 \\
Russian imports & 2600 & 0.56 & 350 \\
Inner Mongolia cooperation & 80 & 0.15 & 100 \\
Shuangyang foreign investment cooperation & 55 & 0.21 & 25 \\
Total & - & 0.38 & 1000 \\
\hline
\end{tabular}

results, crude oil procurement should first select Russia to import crude oil, followed by Inner Mongolia cooperative oilfield and Jilin oilfield. Other crude oil suppliers are trying to reduce the number of purchases while considering the impact of transportation capacity risks and unexpected risks on production. The final purchase allocation is shown in Table 8. 


\section{Conclusion}

The developments in the field of information and communication technologies have made the processing and transmission of information technology break through the limitations of time and region. The network and globalization of the economy have become an inevitable trend in the development of the world economy. The implementation of crude oil e-commerce procurement can reduce the cost of crude oil procurement, create good economic benefits, improve the management level of enterprises, and improve the market competitiveness of enterprises. This lays a solid foundation for the sustainable development of petrochemical enterprises. Based on the characteristics of crude oil procurement of petrochemical enterprises and the principles established by the evaluation index system, this paper constructs an evaluation index system for the strategic procurement plan of crude oil in petrochemical enterprises. The internal and external environment of a company's crude oil e-commerce procurement was analyzed in depth, and the existing crude oil suppliers and potential suppliers were comprehensively evaluated and the corresponding procurement strategies were formulated. Results of the study show the success of the proposed study, and on the basis of the proposed study, researchers can devise new solutions in the field.

\section{Data Availability}

The datasets used and/or analyzed during the current study are available from the corresponding author on reasonable request.

\section{Conflicts of Interest}

The author declares that he has no conflicts of interest.

\section{References}

[1] S. A. Al-Somali, R. Gholami, and B. Clegg, "A stage-oriented model (SOM) for e-commerce adoption: a study of Saudi Arabian organisations," Journal of Manufacturing Technology Management, vol. 26, no. 1, pp. 2-35, 2015.

[2] L. Kilian and D. P. Murphy, "The role of inventories and speculative trading in the global market for crude oil," Journal of Applied Econometrics, vol. 29, no. 3, pp. 454-478, 2014.

[3] M. J. S. Chandrasekar Subramaniam, "A study of the value and impact of B2B e-commerce: the case of web-based procurement," International Journal of Electronic Commerce, vol. 6, no. 4, pp. 19-40, 2002.

[4] L. Lu and T. Reardon, "An economic model of the evolution of food retail and supply chains from traditional shops to supermarkets to E-commerce," American Journal of Agricultural Economics, vol. 100, no. 5, pp. 1320-1335, 2018.

[5] W.-T. Wang, Y.-S. Wang, and E.-R. Liu, "The stickiness intention of group-buying websites: the integration of the commitment-trust theory and e-commerce success model," Information \& Management, vol. 53, no. 5, pp. 625-642, 2016.

[6] H. An, W. Zhong, Y. Chen, H. Li, and X. Gao, "Features and evolution of international crude oil trade relationships: a trading-based network analysis," Energy, vol. 74, no. 1, pp. 254-259, 2014.

[7] Q. Guan, H. An, X. Gao, S. Huang, and H. Li, "Estimating potential trade links in the international crude oil trade: a link prediction approach," Energy, vol. 102, no. 1, pp. 406-415, 2016.

[8] C. Valmohammadi and S. Dashti, "Using interpretive structural modeling and fuzzy analytical process to identify and prioritize the interactive barriers of e-commerce implementation," Information \& Management, vol. 53, no. 2, pp. 157-168, 2016.

[9] L. Roselli, D. Carlucci, and B. C. De Gennaro, "What is the value of extrinsic olive oil cues in emerging markets? Empirical evidence from the U.S. E-Commerce retail market," Agribusiness, vol. 32, no. 3, pp. 329-342, 2016.

[10] A. Davila, M. Gupta, and R. Palmer, "Moving procurement systems to the Internet: the adoption and use of e-procurement technology models," European Management Journal, vol. 21, no. 1, pp. 11-23, 2003.

[11] S. X. Xu and G. Q. Huang, "Efficient multi-attribute multiunit auctions for B2B E-commerce logistics," Production and Operations Management, vol. 26, no. 2, pp. 292-304, 2017.

[12] H. O. Awa, O. U. Ojiabo, and B. C. Emecheta, "Integrating TAM, TPB and TOE frameworks and expanding their characteristic constructs for e-commerce adoption by SMEs," Journal of Science \& Technology Policy Management, vol. 6, no. 1, pp. 76-94, 2015.

[13] H. G. Huntington, "Crude oil trade and current account deficits," Energy Economics, vol. 50, pp. 70-79, 2015.

[14] S.-J. Eom, S.-C. Kim, and W.-S. Jang, "Paradigm shift in main contractor-subcontractor partnerships with an e-procurement framework," KSCE Journal of Civil Engineering, vol. 19, no. 7, pp. 1951-1961, 2015.

[15] R. Du, Y. Wang, G. Dong et al., "A complex network perspective on interrelations and evolution features of international oil trade, 2002-2013," Applied Energy, vol. 196, no. 6, pp. 142-151, 2017.

[16] R. Du, G. Dong, L. Tian et al., "A complex network perspective on features and evolution of world crude oil trade," Energy Procedia, vol. 104, no. 12, pp. 221-226, 2016.

[17] M. A. Rahman and L. Casanovas, "Strategies to predict E-commerce inventory and order planning," International Journal of Technology Diffusion, vol. 8, no. 4, pp. 17-30, 2017.

[18] P. Yan and Z. Aihui, "An analysis of purchasing model of furniture enterprises based on E-commerce platform," Forest Engineering, vol. 3, no. 1, p. 38, 2015. 